\title{
REVIEW
}

Open Access

\section{Role of the intestinal microbiome in colorectal cancer surgery outcomes}

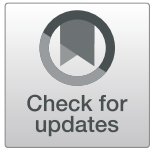

\author{
Lelde Lauka ${ }^{1,2} \mathbb{D}$, Elisa Reitano ${ }^{1} \mathbb{B}$, Maria Clotilde Carra ${ }^{3}$, Federica Gaiani ${ }^{4} \mathbb{D}$, Paschalis Gavriilidis ${ }^{5} \mathbb{D}$, \\ Francesco Brunetti ${ }^{1,2}$ (D) Gian Luigi de'Angelis ${ }^{4^{*}}$ (D), Iradj Sobhani ${ }^{2,6}$ (D) and Nicola de'Angelis ${ }^{1,2}$ (D)
}

\begin{abstract}
Objectives: Growing evidence supports the role of the intestinal microbiome in the carcinogenesis of colorectal cancers, but its impact on colorectal cancer surgery outcomes is not clearly defined. This systematic review aimed to analyze the association between intestinal microbiome composition and postoperative complication and survival following colorectal cancer surgery.

Methods: A systematic review was conducted according to the 2009 PRISMA guidelines. Two independent reviewers searched the literature in a systematic manner through online databases, including Medline, Scopus, Embase, Cochrane Oral Health Group Specialized Register, ProQuest Dissertations and Theses Database, and Google Scholar. Human studies investigating the association between the intestinal microbiome and the short-term (anastomotic leakage, surgical site infection, postoperative ileus) and long-term outcomes (cancer-specific mortality, overall and disease-free survival) of colorectal cancer surgery were selected. Patients with any stage of colorectal cancer were included. The Newcastle-Ottawa scale for case-control and cohort studies was used for the quality assessment of the selected articles.
\end{abstract}

Results: Overall, 8 studies (7 cohort studies and 1 case-control) published between 2014 and 2018 were included. Only one study focused on short-term surgical outcomes, showing that anastomotic leakage is associated with low microbial diversity and abundance of Lachnospiraceae and Bacteroidaceae families in the non-cancerous resection lines of the stapled anastomoses of colorectal cancer patients. The other 7 studies focused on long-term oncological outcomes, including survival and cancer recurrence. The majority of the studies (5/8) found that a higher level of Fusobacterium nucleatum adherent to the tumor tissue is associated with worse oncological outcomes, in particular, increased cancer-specific mortality, decreased median and overall survival, disease-free and cancer-specific survival rates. Also a high abundance of Bacteroides fragilis was found to be linked to worse outcomes, whereas the relative abundance of the Prevotella-co-abundance group (CAG), the Bacteroides CAG, and the pathogen CAG as well as Faecalibacterium prausnitzii appeared to be associated with better survival.

Conclusions: Based on the limited available evidence, microbiome composition may be associated with colorectal cancer surgery outcomes. Further studies are needed to elucidate the role of the intestinal microbiome as a prognostic factor in colorectal cancer surgery and its possible clinical implications.

Keywords: Intestinal microbiome, Colorectal cancer, Surgical outcomes, Oncological outcomes, Systematic review

\footnotetext{
*Correspondence: gianluigi.deangelis@unipr.it

${ }^{4}$ Gastroenterology and Endoscopy Unit, University Hospital of Parma,

University of Parma, Via Gramsci 14, 43126 Parma, Italy

Full list of author information is available at the end of the article
}

(c) The Author(s). 2019 Open Access This article is distributed under the terms of the Creative Commons Attribution 4.0 International License (http://creativecommons.org/licenses/by/4.0/), which permits unrestricted use, distribution, and reproduction in any medium, provided you give appropriate credit to the original author(s) and the source, provide a link to the Creative Commons license, and indicate if changes were made. The Creative Commons Public Domain Dedication waiver (http://creativecommons.org/publicdomain/zero/1.0/) applies to the data made available in this article, unless otherwise stated. 


\section{Background}

In recent years, several studies have shown the impact of the intestinal microbiome on host health and disease development. The human intestinal microbiome is a complex community of bacteria, archaea, viruses, and eukaryotes that is subject-specific and stable in healthy individuals [1]. Disturbances in the balance of the composition and function of the microbiome are associated with the onset of various pathologies, including obesity, Crohn's disease, and gastrointestinal malignancies [2]. Indeed, a growing amount of evidence supports the role of the microbiome as a risk factor for the carcinogenesis of several malignancies, including colorectal cancers [3]. Conversely, the impact of the microbiome on the occurrence of postoperative complications and on the development of local recurrence after colorectal cancer surgery is not clearly defined.

Assessing whether the microbiome is a potential risk factor for postoperative complications of colorectal surgeries could lead to modifying perioperative care, as multiple perioperative interventions, such as mechanical bowel preparation (MBP) and antibacterial therapy (ABT), drastically influence microbiome composition, especially bacterial diversity $[4,5]$. MBP, with or without ABT, is widely but empirically implemented before colorectal surgery to carry out a "clean" intervention that minimizes the risk of fecal contamination of the operative field, particularly during the anastomosis preparation. However, it has been shown that the loss of bacterial diversity could be a risk factor for postoperative complications, questioning the role of preoperative MBP and ABT [4].

Studies of animal models have shown that a eubiotic state is important for normal wound healing, including anastomosis repair after colorectal surgery [6]. Bacterial competition and cooperation can either promote or hamper wound healing during the inflammatory phase, influencing cellular activation and fibrosis in the wound repair process [5]. In the eubiotic state, bacteria remain harmless and do not cause infections, whereas following changes in the local environment and the induction of dysbiosis, by surgical injury for example, bacterial invasion and tissue inflammation take place [7].

Due to the major role of the microbiome in inflammation and wound healing [8], it is plausible that dysbiosis may be related to the development of colorectal surgery complications, such as anastomotic leakage (AL), surgical site infections (SSI), and prolonged postoperative ileus (PPI) $[9,10]$.

The composition of the intestinal microbiome may also impact the long-term outcomes of surgical treatments of colorectal cancer. Local recurrences of colorectal cancer are reported in $1-23 \%$ of cases after curative surgery [11]; this rate varies depending on tumor stage, localization, neoadjuvant and adjuvant therapies, and surgical technique [12]. Moreover, the occurrence of major postoperative complications has been related to worse oncological outcomes and overall and disease-free survival [13]. Of note, regarding the occurrence of postoperative complications, the administration of adjuvant chemotherapy may be delayed or contraindicated due to an insufficient patient performance status, which impacts prognosis [14].

In this context, it would be important to characterize the intestinal microbiome not only as a potential contributor to early postoperative complications (e.g., AL) but also as a potential marker of cellular and molecular mechanisms linked to local recurrence.

The present systematic review aims to analyze the available literature about the intestinal microbiome and its association with postoperative complications and long-term oncological outcomes after colorectal cancer surgery. To our knowledge, there is no existing review on the topic that has been performed with a systematic approach.

\section{Materials and methods}

Data sources and search strategy

A systematic review was performed following the Cochrane collaboration-specific protocol [15] and was reported according to the Preferred Reporting Items for Systematic Reviews and Meta-Analyses (PRISMA) statement.

Studies that investigated the association between the intestinal microbiome and surgical outcomes/postoperative complications and/or oncological outcomes/survival in colorectal cancer patients were searched in the following databases without date restrictions: Medline (through PubMed), Scopus, Embase, Cochrane Oral Health Group Specialized Register, ProQuest Dissertations and Theses Database, and Google Scholar. A specific research equation was used for each database, using the following keywords and $\mathrm{MeSH}$ terms: microbiome, microbiota, colorectal, surgery, surgical procedures, operative surgical procedures, general surgery, complications, anastomotic leak, surgical wound infection, surgical site infection(s), ileus, recurrence, mortality, survival, outcomes.

According to the PICOS schema, the following criteria were used for the literature search and selection:

P, population: adult patients with colorectal cancer who underwent surgical resection. Any stage of colorectal cancer (according to the AJCC classification) was considered [16].

I, intervention: analysis of the luminal or mucosaassociated microbiome from fecal samples or colorectal 
tissues. Both culture-dependent and genome sequencing methods were considered.

$\mathrm{C}$, comparisons: patients with and without postoperative complications and patients with different bacterial DNA loads in their microbiome samples. O, outcome(s): postoperative complications 90 days after surgery, including AL, SSI, and PI. Long-term outcomes comprised overall survival (OS), cancer-specific survival (CSS), disease-free survival (DFS), and recurrence-free survival (RFS).

S, study design: randomized and non-randomized clinical trials, including cohort and case-control studies.

Studies that investigated colorectal diseases other than cancer, evaluating the impact of probiotic treatments, or focusing exclusively on the pathogenesis of colorectal cancer were not eligible for inclusion. The search was limited to human studies published in English. Then, the literature review was completed by using the "related articles" function in PubMed, to ensure an extensive approach. Moreover, the reference lists of the eligible records and pertinent review articles that were not included in this study were double-checked to identify potential additional articles for inclusion.

The literature search and selection were performed by two independent reviewers (LL and ER). Records were removed from the selection if both reviewers excluded the articles at the title/abstract screening levels. Disagreement was resolved via a discussion with a third reviewer (NdeA). Overall, the concordance rate between the two reviewers was $95 \%$.

Details of the study protocol are registered in the International prospective register of systematic reviews, PROSPERO (ID number CRD42019117597).

\section{Data extraction}

Both reviewers performed an independent full-text analysis and data extraction by filling in an electronic database. Extracted data included the first author's name, year of publication, number of patients, type of microbiome, type of postoperative complications (AL, SSI, PPI), and oncological outcomes (recurrence, OS, DFS). Characterization of both the luminal microbiome (LM, fecal microbiome) and the mucosa-associated microbiome (MAM) was considered and described [17].

$\mathrm{AL}$ is defined as a defect in the bowel wall at the anastomotic site (including suture and staple lines of neorectal reservoirs) leading to communication between the intraluminal and extraluminal compartments [18].

SSI refers to an infection that develops 30 days after the surgery (or 1 year after the surgery if an implant has been placed) and is classified as superficial incisional SSI, deep incisional SSI, and organ/space SSI [19].
PPI is generally characterized by the presence of nausea and vomiting, inability to tolerate oral dietary intake, abdominal distension, and delayed passage of flatus and stool during the postoperative period [20].

\section{Study quality assessment and risk of bias}

Two reviewers (LL and ER) carried out the study quality assessment and risk of bias evaluation of the selected articles. According to the study design, the New CastleOttawa scale (NOS) was used [21].

\section{Results}

\section{Literature search and selection}

The initial search yielded 383 results; after removing duplicates, 382 articles were screened for eligibility based on title and abstract, and 21 articles were retrieved for a full-text evaluation. A total of 8 studies fulfilled the inclusion criteria and were finally included in the review [22-29] (Fig. 1). The excluded articles and detailed reasons for exclusion are reported in Additional file 1: Table S1.

\section{Study characteristics}

The selected studies were published between 2014 and 2018, and there were 7 cohort studies [22-28] and 1 case-control [29]. The studies were carried out in Europe $(n=3)$, North America $(n=2)$, and Asia Pacific $(n=3)$. The general characteristics of the studies examined are summarized in Table 1 . The overall total number of patients considered is 3263 .

Of the 8 selected articles, only one analyzed shortterm outcomes, more specifically, the rate of AL [29]. No data were reported concerning SSI or PI. The other 7 articles focused on oncological long-term outcomes, that is, overall survival, mortality, and recurrence.

All of the included studies used microbial DNA analysis as a method for microbiome detection and characterization. Three articles studied the general composition of the microbiome in the sample, while 5 others looked for a particular bacterium, as shown in Table 1. In the first three studies $[23,26,29]$, cultureindependent profiling of bacterial communities in tissue samples was performed using amplification of bacterial $16 \mathrm{~S}$ ribosomal RNS gene (16S rRNS). While Flemer et al. [23] and Praagh et al. [29] targeted variable regions $\mathrm{V} 3$ and V4 of the gene, Wei et al. [26] sequenced only V4 region. In the studies of Wei et al. and Praagh et al., statistical analysis was performed on the family, genus, and species level, whereas Flemer et al. did genus-based analysis. Rest of the studies [22, 24, 25, 27, 28] focused on detection of specific bacterial genus-Bifidobacterium [24] -or species-Fusobacterium nucleatum (Fn) [22, 25, $27,28]$. DNA detection and bacteria quantification were performed by real-time quantitative PCR (qPCR) method 


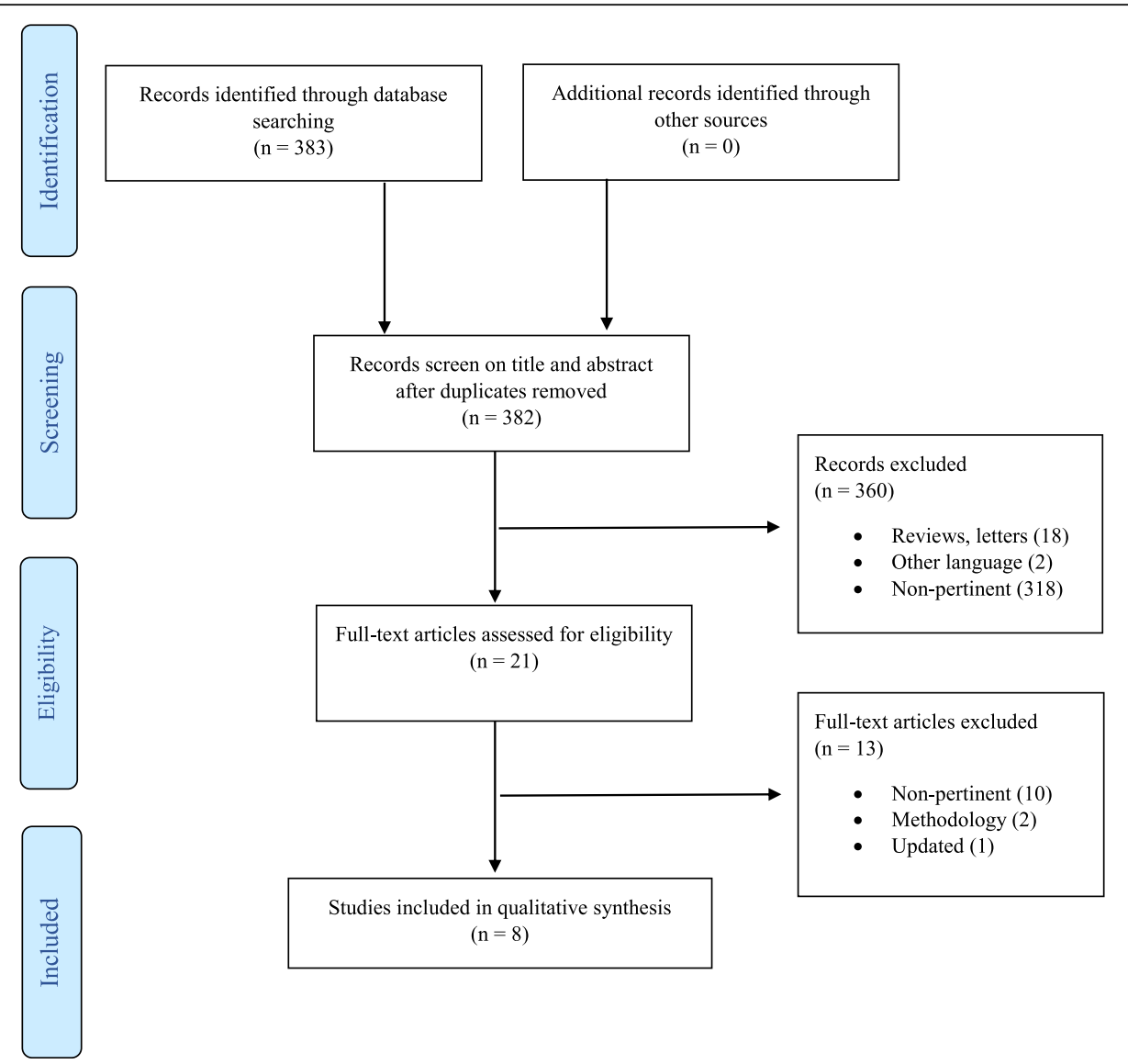

Fig. 1 PRISMA flow diagram for study search, selection, inclusion, and exclusion. Example or search terms strategy: (("microbiota"[MeSH Terms] OR "microbiota"[All Fields] OR "microbiome"[All Fields]) AND colorectal[All Fields]) AND (("surgery"[Subheading] OR "surgery"[All Fields] OR "surgical procedures, operative"[MeSH Terms] OR ("surgical"[All Fields] AND "procedures"[All Fields] AND "operative"[All Fields]) OR "operative surgical procedures"[All Fields] OR "surgery"[All Fields] OR "general surgery"[MeSH Terms] OR ("general"[All Fields] AND "surgery"[All Fields]) OR "general surgery"[All Fields]) OR ("complications"[Subheading] OR "complications"[All Fields]) OR ("anastomotic leak"[MeSH Terms] OR ("anastomotic"[All Fields] AND "leak"[All Fields]) OR "anastomotic leak"[All Fields]) OR ("surgical wound infection"[MeSH Terms] OR ("surgical"[All Fields] AND "wound"[All Fields] AND "infection"[All Fields]) OR "surgical wound infection"[All Fields]) OR ("ileus"[MeSH Terms] OR "ileus"[All Fields]) OR ("recurrence"[MeSH Terms] OR "recurrence"[All Fields]) OR ("mortality"[Subheading] OR "mortality"[All Fields] OR "mortality"[MeSH Terms]) OR ("mortality"[Subheading] OR "mortality"[All Fields] OR "survival"[All Fields] OR "survival"[MeSH Terms]) OR outcomes[All Fields])

targeting 16S rRNA gene DNA sequence of Bifidobacterium and different $F n$ genes (16 s rRNA gene, nusG gene). In all studies but one [29], differences in microbiome composition were analyzed according to tumor stage. The main results of the selected studies are summarized in Table 2.

\section{Microbiome and short-term outcomes}

Only one study published by van Praagh et al. investigated the relationship between a short-term surgical outcome, namely $\mathrm{AL}$, and the composition of the intestinal microbiome [29]. The article reports a secondary analysis of data obtained from a previously published study [30] and investigates the association of intestinal microbiome with the development of colorectal AL depending on treatment method. The authors analyzed AL that required reintervention in patients who underwent colorectal surgery with or without the placement of a Cseal, a bioresorbable sheath stapled to the anastomosis. The mucosa-associated microbiome was analyzed from the stapled colorectal "donut." The results of this study showed that in the patient group without the C-seal, $\mathrm{AL}$ was significantly associated with a lower biodiversity of the microbiome and a higher abundance of the mucindegrading microbiome families Lachnospiraceae and Bacteroidaceae compared with matched patients who did not develop AL. Conversely, in the patient group receiving the C-seal, who showed a slightly higher rate of AL than the non-C-seal group, no association between $\mathrm{AL}$ and microbiome composition was detected. Only a few opportunistic pathogenic groups with a low abundance were associated with AL, particularly Prevotella oralis. The authors concluded that in patients who underwent colorectal surgery without C-seal placement, 
Table 1 Characteristics of the included studies

\begin{tabular}{|c|c|c|c|c|c|c|c|c|c|c|}
\hline $\begin{array}{l}\text { Authors, } \\
\text { year }\end{array}$ & $\begin{array}{l}\text { Study } \\
\text { design }\end{array}$ & $\begin{array}{l}\text { No. of } \\
\text { patients }\end{array}$ & $\begin{array}{l}\text { Tumor } \\
\text { stage }\end{array}$ & $\begin{array}{l}\text { Microbiome } \\
\text { type, tissue } \\
\text { sample }\end{array}$ & $\begin{array}{l}\text { Detection } \\
\text { method }\end{array}$ & Bacteria $^{2}$ & $\begin{array}{l}\text { Short-term } \\
\text { surgical } \\
\text { outcomes }\end{array}$ & $\begin{array}{l}\text { Long-term } \\
\text { oncological } \\
\text { outcomes }\end{array}$ & $\begin{array}{l}\text { Mean } \\
\text { (SD) or } \\
\text { median } \\
\text { (range) } \\
\text { follow- } \\
\text { up }\end{array}$ & $\begin{array}{l}\text { Adjustments on } \\
\text { covariates }\end{array}$ \\
\hline $\begin{array}{l}\text { Flanagan } \\
\text { et al., } \\
2014\end{array}$ & Cohort & 32 & $\begin{array}{l}\text { Dukes } \\
\text { staging } \\
\text { A-D }\end{array}$ & MAM, tumor & $\begin{array}{l}\text { Bacterial } \\
\text { DNA, } \\
\text { qPCR }\end{array}$ & $\begin{array}{l}\text { Fusobacterium } \\
\text { nucleatum }\end{array}$ & Not reported & $\begin{array}{c}\text { - Overall } \\
\text { survival }\end{array}$ & 5 years & Not specified \\
\hline $\begin{array}{l}\text { Flemer } \\
\text { et al., } \\
2018\end{array}$ & Cohort & 47 & $\begin{array}{l}\text { AJCC } \\
\text { I-IV }\end{array}$ & MAM, tumor & $\begin{array}{l}\text { Bacterial } \\
\text { DNA, V3- } \\
\text { V4 16S } \\
\text { rRNA }\end{array}$ & CAG & Not reported & $\begin{array}{l}\text { - Overall } \\
\text { survival }\end{array}$ & $\begin{array}{l}1371 \\
\text { days } \\
(67- \\
1792 \\
\text { days) }\end{array}$ & $\begin{array}{l}\text { Tumor stage, age, } \\
\text { gender, treatment } \\
\text { with chemotherapy } \\
\text { and/or radiotherapy } \\
\text { and cancer site }\end{array}$ \\
\hline $\begin{array}{l}\text { Kosumi } \\
\text { et al., } \\
2018\end{array}$ & Cohort & 1313 & $\begin{array}{l}\text { AJCC } \\
\text { I-IV }\end{array}$ & MAM, tumor & $\begin{array}{l}\text { Bacterial } \\
\text { DNA, } \\
\text { qPCR }\end{array}$ & Bifidobacterium & Not reported & $\begin{array}{l}\text { - Cancer- } \\
\text { specific } \\
\text { mortality } \\
\text { - Overall } \\
\text { mortality }\end{array}$ & $\begin{array}{l}14.3 \\
\text { years } \\
(10- \\
18.3 \\
\text { years) }\end{array}$ & $\begin{array}{l}\text { Microsatellite instability } \\
\text { status, CpG island } \\
\text { methylator phenotype, } \\
\text { long-interspersed nu- } \\
\text { cleotide element-1 } \\
\text { methylation, KRAS, } \\
\text { BRAF, and PIK3CA } \\
\text { mutations. }\end{array}$ \\
\hline $\begin{array}{l}\text { Mima } \\
\text { et al., } \\
2016\end{array}$ & Cohort & 1069 & $\begin{array}{l}\text { AJCC } \\
\text { I-IV }\end{array}$ & MAM, tumor & $\begin{array}{l}\text { Bacterial } \\
\text { DNA, } \\
\text { qPCR }\end{array}$ & $\begin{array}{l}\text { Fusobacterium } \\
\text { nucleatum }\end{array}$ & Not reported & $\begin{array}{l}\text { - Cancer- } \\
\text { specific } \\
\text { mortality } \\
\text { - Overall } \\
\text { mortality }\end{array}$ & $\begin{array}{l}10.7 \\
\text { years } \\
(7-15.8 \\
\text { years })\end{array}$ & $\begin{array}{l}\text { Age, sex, year of } \\
\text { diagnosis, family } \\
\text { history of colorectal } \\
\text { carcinoma in a first- } \\
\text { degree relative, tumor } \\
\text { location, microsatellite } \\
\text { instability (MSI, mis- } \\
\text { match repair defi- } \\
\text { ciency), CpG island } \\
\text { methylator phenotype } \\
\text { (CIMP), KRAS, BRAF, } \\
\text { and PIK3CA mutations, } \\
\text { and LINE-1 hypome- } \\
\text { thylation (low-level } \\
\text { methylation). }\end{array}$ \\
\hline $\begin{array}{l}\text { Van } \\
\text { Praagh } \\
\text { et al., } \\
2017\end{array}$ & $\begin{array}{l}\text { Case- } \\
\text { control }\end{array}$ & 118 & $\begin{array}{l}\text { Not } \\
\text { specified }^{3}\end{array}$ & $\begin{array}{l}\text { MAM, } \\
\text { anastomosis }\end{array}$ & $\begin{array}{l}\text { Bacterial } \\
\text { DNA, V3- } \\
\text { V4 16S } \\
\text { rRNA }\end{array}$ & All & $\begin{array}{l}\text { Anastomotic } \\
\text { leakage }\end{array}$ & Not reported & $\begin{array}{l}\text { Not } \\
\text { reported }\end{array}$ & Not specified \\
\hline $\begin{array}{l}\text { Wei et al., } \\
2016\end{array}$ & Cohort & 180 & $\begin{array}{l}\text { AJCC } \\
\text { I-IV }\end{array}$ & MAM, tumor & $\begin{array}{l}\text { Bacterial } \\
\text { DNA, V4 } \\
16 S \text { rRNA }\end{array}$ & All & Not reported & $\begin{array}{l}\text { - Overall } \\
\text { survival } \\
\text { - Disease- } \\
\text { free } \\
\text { survival }\end{array}$ & $\begin{array}{l}47 \\
\text { months } \\
\text { (36-59 } \\
\text { months) }\end{array}$ & Not specified \\
\hline $\begin{array}{l}\text { Yan et al., } \\
2017\end{array}$ & Cohort & 208 & $\begin{array}{l}\text { AJCC } \\
\text { III-IV }\end{array}$ & MAM, tumor & $\begin{array}{l}\text { Bacterial } \\
\text { DNA, } \\
\text { qPCR }\end{array}$ & $\begin{array}{l}\text { Fusobacterium } \\
\text { nucleatum }\end{array}$ & Not reported & $\begin{array}{l}\text { - Cancer- } \\
\text { specific } \\
\text { survival } \\
\text { - Disease- } \\
\text { free } \\
\text { survival }\end{array}$ & $\begin{array}{l}\text { Not } \\
\text { reported }\end{array}$ & Not specified \\
\hline $\begin{array}{l}\text { Yu et al., } \\
2017\end{array}$ & Cohort & 296 & $\begin{array}{l}\text { AJCC } \\
\|-I\|\end{array}$ & MAM, tumor & $\begin{array}{l}\text { Bacterial } \\
\text { DNA, } \\
\text { qPCR }\end{array}$ & $\begin{array}{l}\text { Fusobacterium } \\
\text { nucleatum }\end{array}$ & Not reported & $\begin{array}{l}\text { Recurrence- } \\
\text { free } \\
\text { survival }\end{array}$ & $\begin{array}{l}\text { Not } \\
\text { reported }\end{array}$ & Not specified \\
\hline
\end{tabular}

AJCC, American Joint Committee on Cancer; MAM, mucosa-associated microbiome; $C A G$, tissue-associated microbial co-abundance groups; $q P C R$, quantitative polymerase chain reaction

'Patients included in the analysis of the microbiome and its association with short- or long-term outcomes

${ }^{2}$ Bacteria analyzed for an association with short- or long-term outcomes

${ }^{3}$ The study also included 6 non-oncological patients 
Table 2 Summary of the main results of the included studies

\begin{tabular}{|c|c|c|c|}
\hline $\begin{array}{l}\text { Authors, } \\
\text { year }\end{array}$ & Bacteria $^{1}$ & $\begin{array}{l}\text { Bacterial characteristics in } \\
\text { tissues }\end{array}$ & $\begin{array}{l}\text { Association be } \\
\text { composition a }\end{array}$ \\
\hline \multicolumn{4}{|c|}{ Short-term outcomes } \\
\hline $\begin{array}{l}\text { Van } \\
\text { Praagh } \\
\text { et al., } \\
2017\end{array}$ & $\begin{array}{l}\text { Lachnospiraceae } \\
\text { Bacteroidaceae }\end{array}$ & $\begin{array}{l}\text { High abundance }+ \\
\text { Low microbial diversity in } \\
\text { patients with or without C- } \\
\text { seal }\end{array}$ & Not reported \\
\hline
\end{tabular}

Long-term outcomes

Flanagan F. nucleatum
et al.,
2014

Flemer Pathogen CAG

et al., Prevotella CAG

2018 Bacteroides CAG

Firmicutes $C A G$
High vs. low or fold increase from normal

Relative abundance

Not specified between patients with no/low or high F. nucleatum, in TNM/ Dukes staging.

Difference in Bifidobacteria was not associated with disease stage

et al.,

Bifidobacterium Negative vs. low vs. high DNA weight

Mima

F. nucleatum

High vs. low vs. negative DNA load

et al.,

Wei et al., B. fragilis 2016 F. nucleatum

F. prausnitzii
High vs. low abundance
The amount of tissue F. NUCLEATUM DNA was associated with higher $\mathrm{pT}$ stage $(p=0.0007)$. The association was not statistically significant with $\mathrm{pN}$ or M stage.

- High abundance of F. nucleatum was significantly correlated with positive lymph node metastasis - High abundance of F. prausnitzii and $F$. nucleatum was significantly correlated with worse depth of invasion

\author{
- AL patients without a C-seal showed a signifi \\ cant lower microbial diversity, more Bacter \\ oides, more Lachnospiraceae, and less Prevotella \\ and Streptococci than C-seal patients who \\ developed AL. \\ - AL cases of non-C-seal patients seem to be \\ almost without exception dominated by \\ Lachnospiraceae and Bacteroidaceae with \\ correspondingly low microbial diversity scores \\ - Relation between the composition of the \\ intestinal microbiota and the subsequent \\ development of AL after stapled colorectal \\ anastomoses, but only in patients who \\ underwent surgery without the additional \\ C-seal that covered the anastomoses
}

- A significant difference in survival between patients without detected $F$. nucleatum in tumor tissue or low fold increase vs. those with high fold increase.

- Median survival of subjects with high F. nucleatum fold increase is 2 years, whereas all subjects with low tumor to normal ratio survive more than 3 years ( $H R=19.96,95 \%$ $\mathrm{Cl}=1.42-281.42, p=0.0266)$.

- Pathogen CAG-type microbiota was associated with longer survival $(\mathrm{HR}=0.8, \mathrm{Cl}=0.6-1.06$; $p=0.12$ )

- Prevotella CAG-type microbiota was associated with longer survival $(\mathrm{HR}=0.36, \mathrm{Cl}=0.12-1.1$; $p=0.075$.

- Bacteroidetes CAG was associated with longer survival $(\mathrm{HR}=0.75, \mathrm{Cl}=0.58-1.03 ; p=0.078)$.

- Firmicutes CAG 2 was associated with shorter survival $(\mathrm{HR}=1.52, \mathrm{Cl}=0.84-2.75 ; p=0.17)$

No significant associations of the amount of Bifidobacteria with colorectal cancer-specific mortality or overall mortality

- Compared with F. nucleatum-negative cases, F. nucleatum-high cases had an $\mathrm{HR}=1.58$ (95\% $\mathrm{Cl}=1.04-2.39)$ for cancer-specific mortality

- A higher amount of tissue F. nucleatum DNA was associated with shorter colorectal cancerspecific survival ( $p=0.023$ ) but no difference in overall mortality rate

- Higher level of B. fragilis (9.75\% vs. 2.62\%, FDR $=0.017)$ in non-survival group than in survival group,

- F. prausnitzii (2.96\% vs. $0.92 \%, F D R=0.028)$ and Methylobacterium suomiense (1.91\% vs. $0.78 \%, F D R=0.098$ ) were more abundant in the survival group.

- F. nucleatum was higher in non-survival group than survival group (5.66\% vs. $1.08 \%$, FDR $=0.076$ ) and it exhibited a greater abundance in the recurrence group than in survival group ( $5.10 \%$ vs. $1.08 \%, F D R=0.08)$

- B. fragilis and F. prausnitzii might be correlated with patient's survival in CRC

- 3-year OS was significantly lower in patients with high $B$. fragilis and $F$. nucleatum than in those with low abundance of these two 
Table 2 Summary of the main results of the included studies (Continued)

\begin{tabular}{|c|c|c|c|c|}
\hline $\begin{array}{l}\text { Authors, } \\
\text { year }\end{array}$ & Bacteria $^{1}$ & $\begin{array}{l}\text { Bacterial characteristics in } \\
\text { tissues }\end{array}$ & $\begin{array}{l}\text { Association between microbiota } \\
\text { composition and tumor stage }\end{array}$ & Results \\
\hline & & & & $\begin{array}{l}\text { microbiota }(p=0.001, p=0.003) \text {. } \\
\text { - Low abundance of } F \text {. prausnitzii showed } \\
\text { worse 3-year OS, }(p=0.06) \text {. } \\
\text { - B. fragilis }(\mathrm{HR}=2.01 ; 95 \% \mathrm{Cl}=1.02-3.96 ; \\
p=0.044) \text { and } F . \text { nucleatum }(\mathrm{HR}=1.99 ; 95 \% \\
\mathrm{Cl}=1.02-3.87 ; p=0.042) \text { were independent } \\
\text { predictor of the 3-year OS } \\
\text { - B. fragilis }(\mathrm{HR}=2.04 ; 95 \% \mathrm{Cl}=1.11-3.73 ; \\
p=0.021) \text { and } F . \text { nucleatum }(\mathrm{HR}=1.82 ; 95 \% \\
\mathrm{Cl}=1-3.34 ; p=0.05) \text { were associated with } \\
\text { poor 3-year DFS both }\end{array}$ \\
\hline $\begin{array}{l}\text { Yan et al., } \\
2017\end{array}$ & F. nucleatum & High vs. low level & $\begin{array}{l}\text { - In both stage III and IV tumor, } \\
\text { F. nucleatum level was } \\
\text { significantly higher in CRC } \\
\text { tissues than in adjacent normal } \\
\text { tissues } \\
\text { - F. nucleatum was found to } \\
\text { significantly associated with tumor } \\
\text { invasion }(p=0.015) \text {, LNM status } \\
(p=0.008) \text {, and distant metastasis } \\
(p=0.020) \text {. } \\
\text { - Stage IIIA patients with low F. } \\
\text { nucleatum level had no better } \\
\text { CSS and DFS than those with } \\
\text { high F. nucleatum level } \\
\text { - High F. nucleatum level was } \\
\text { significantly associated with } \\
\text { worse CSS and DFS in stage IIIB } \\
\text { and IV patients }\end{array}$ & $\begin{array}{l}\text { - Patients with high } F . \text { nucleatum level had a } \\
\text { significantly worse CSS and DFS than those } \\
\text { with low F. nucleatum level } \\
\text { For CSS: HR }=2.22 ; 95 \% \mathrm{Cl}=1.48-3.32 \\
p<0.001 \\
\text { For DFS: HR }=2.0 ; 95 \% \mathrm{Cl}=1.39-2.86 \text {; } \\
p<0.001\end{array}$ \\
\hline $\begin{array}{l}\text { Yu et al., } \\
2017\end{array}$ & F. nucleatum & High vs. low amount & $\begin{array}{l}\text { The amount of } F \text {. nucleatum was } \\
\text { positively associated with the AJCC } \\
\text { stage and tumor size }\end{array}$ & $\begin{array}{l}\text { - The } 5 \text {-year RFS was substantially shorter in } \\
\text { the F. nucleatum-high group than the } F \text {. } \\
\text { nucleatum-low group. } \\
\text { - F. nucleatum was an independent predictor } \\
\text { of CRC aggressiveness with significant HR } \\
\text { for predicting clinical outcome. Its predictive } \\
\text { value was comparable with that of the AJCC } \\
\text { stage }\end{array}$ \\
\hline
\end{tabular}

$A L$, anastomotic leakage; $C A G$, tissue-associated microbial co-abundance groups; $C R C$, colorectal cancer; $H R$, hazard ratios; OS, overall survival; $C S S$, cancer-specific survival; DFS, disease-free survival; RFS, recurrence-free survival; NS, not stated in the manuscript; LNM, lymph node metastasis

${ }^{1}$ Bacteria specifically associated with analyzed outcome

a bacterial composition of the intestinal microbiome consisting of $60 \%$ or more Lachnospiraceae and Bacteroidaceae is a predictive factor for AL. The lack of this association in $\mathrm{C}$-seal patients may be explained by the effect of C-seal placement, which creates a new ecosystem that consequently influences and alters the composition of the resident microbiome [29]. Although the largest proportion of patients had colorectal cancer, it is worth noting that 3 patients in each group underwent surgery for non-oncological colorectal diseases.

\section{Microbiome and long-term outcomes}

High heterogeneity was found in terms of considered outcomes and detected bacteria in studies evaluating long-term outcomes of colorectal cancer surgery in relation to intestinal microbiome.

The bacterium most frequently studied in cancer samples is Fusobacterium nucleatum [22, 25-28] (F. nucleatum). Studies have shown that F. nucleatum abundance increases as the disease progresses from an adenoma to cancer [22]. Levels of F. nucleatum are found to be higher in higher pT stages of cancer [25]. However, a study by Flanagan et al. found discordant results showing no differences between $F$. nucleatum levels and tumor stage or mutation status of KRAS and BRAF [22]. All studies investigating the role of $F$. nucleatum confirmed that higher levels of F. nucleatum in tumor samples correlated with worse outcomes in terms of OS, DFS, or cancer-specific survival [22, 25-28], with hazard ratios ranging from 1.58 to 19.96 (Table 2). An unfavorable prognosis could also be linked to the fact that $F$. nucleatum helps to activate autophagy-related pathways in colorectal cancer patients, promoting chemoresistance to oxaliplatin and 5-FU [28].

One study investigated the concentrations of Bifidobacterium, whose presence in tumor samples has been linked to the presence of signet ring cells [24]. In this study, Kosumi et al. reported that Bifidoacterium was 
found in $30 \%$ of the tumor samples, but no statistically significant correlation was noted in terms of the immune response or in the survival analysis (considering both cancer-specific survival and overall mortality).

Another study investigated the co-abundance groups (CAGs) of different bacteria [23]. The Prevotella CAG, pathogen CAG, and Bacteroidetes CAG were associated with improved survival. Although the presence of these specific CAGs has been linked to inflammatory response activation and high levels of Prevotella, pathogen CAGs were shown to positively influence cancer-related survival. Other bacteria, such as Faecalibacterium prausnit$z i i$, were correlated with a better survival outcome [26].

\section{Study quality assessment}

Based on the Newcastle-Ottawa Quality assessment scale (NOS), one study received $8 / 9$ stars, three studies received $6 / 9$, three studies received $5 / 9$, and one study received 4/9. The details are displayed in Additional file 1 Table S2. It must be stressed that a high heterogeneity in the study designs, study populations, analyzed microbiomes, and outcomes was observed. All included studies were retrospective cohort or case-control studies.

\section{Discussion}

The present systematic review is the first, to our knowledge, to analyze the existing literature about the intestinal microbiome and its association with short- and long-term outcomes after colorectal cancer surgery in a systematic manner.

Literature about the impact of microbiome diversity on the occurrence of postoperative complications after colorectal cancer surgery is very limited. Only one study focused on the relationship between the composition of the microbiome and AL [29] and showed that a low microbial diversity and high abundances of Lachnospiraceae and Bacteroidaceae were significantly related to AL. These findings were used for a predictive analysis, which revealed that samples with a total sum of Lachnospiraceae and Bacteroidaceae higher than $60 \%$ and a Simpson diversity score on the family level $<0.75$ are prone to developing $\mathrm{AL}$, with an odds ratio of 28 (95\% confidence interval not reported). Interestingly, both bacterial families are normal habitants of the intestinal microbiome and are important for the healthy functioning of the colonic epithelium, with Faecalibacterium prausnitzii and Eubacterium rectale (Lachnospiraceae family) being the two most common species in the human gut [31]. The Lachnospiraceae family is rich in butyrate-producing bacteria that provide a crucial energy source for colon epithelial cells that is essential for the maintenance of gut barrier functions and immunomodulatory and antiinflammatory properties. To explain the findings with possible pathophysiological effects, it would be crucial to compare the composition of the microbiome before and after surgery.

Half of the included studies focused on F. nucleatum and its association with the long-term oncological outcomes of colorectal cancer patients. All studies showed that high concentrations of $F$. nucleatum had a negative impact on survival outcomes and were associated with decreased OS [26], decreased median survival [22], decreased CSS [27], decreased DFS [26, 27], decreased RFS [28], and increased cancer-specific mortality [25]. However, we must be careful in interpreting these results because the available data rarely or only partially considered the many potential confounding factors that can influence survival outcomes.

In recent years, multiple reviews have analyzed the relationship between Fusobacteria and colorectal cancer. Several studies that detected a higher abundance of $F$. nucleatum in colorectal adenomas compared with healthy colorectal tissues [32] suggested the possible involvement of this bacterium in the pathogenesis of colorectal cancer. A study by Flanagan et al. [22] supports this hypothesis, indicating that not only there are higher F. nucleatum levels in individuals with adenomas than in controls but also that $F$. nucleatum levels increase through adenomatous stage progression from a tubular adenoma to a high-grade dysplasia and colorectal cancer. Indeed, $F$. nucleatum is able to invade human epithelial cells, activate the $\beta$-catenin pathway, and trigger oncogenic gene expression using the FadA adhesion virulence factor; consequently, it can stimulate colorectal cancer cell growth [33]. Moreover, a high abundance of $F$. nucleatum is associated with cancer progression and lymph node metastases, as shown in the study by $\mathrm{Li}$ et al. [34]. The majority of the included studies [25-28] also found a significant association of $F$. nucleatum with one or more unfavorable cancer characteristics-advanced stage, tumor invasion, lymph node metastasis, and tumor size. Further important evidence was obtained from the study by $\mathrm{Yu}$ et al. [28], which highlighted the negative impact of $F$. nucleatum on oncological outcomes. This study compared microbiome composition between recurrent and non-recurrent colorectal cancers and found that $F$. nucleatum is the most enriched bacterium in recurrent cases. Moreover, the study suggests that $F$. nucleatum may promote resistance to oxaliplatin and 5-FU chemotherapy regimens via the colorectal cancer cell autophagy pathway, therefore leading to decreased recurrence-free survival.

Another bacterium that was found to be associated with unfavorable oncological outcomes was B. fragilis, as shown in the study by Wei et al. [26]. Like F. nucleatum, $B$. fragilis was also associated with decreased 3-year OS and DFS. However, unlike F. nucleatum, which is an indigenous species in the oral cavity and is associated with 
only pathological changes in the colon and rectum, $B$. fragilis is present in the intestinal microbiome of all healthy individuals. In particular, enterotoxigenic $B$. fragilis (ETBF) has been linked to the development of colorectal cancer. Purcell et al. [35] showed an increased abundance of ETBF in early stage carcinogenic lesions-low-grade dysplasia and tubular adenomas. Viljoen et al. [36] described significantly higher ETBF and $F$. nucleatum levels in individuals with advanced stage III and IV colorectal cancer. Therefore, it remains to be determined whether the worse oncological outcomes described by Wei et al. [26] are due to specific pathways in carcinogenesis or the $B$. fragilis association with advanced cancer stages.

Kosumi et al. [24] analyzed the relationship between the Bifidobacterium genus and colorectal cancer characteristics and outcomes. Bifidobacterium has been of interest in many studies, mainly concerning probiotic administration and their effect on gastrointestinal and extra-digestive pathologies. Bifidobacteria are normal habitants of the intestinal tract and are present from an early age. The imbalance of Bifidobacteria has been associated with several non-oncological diseases [37], but few studies have suggested its association with colorectal cancer. Indeed, it has been shown that there are decreased levels of Bifidobacteria in patients with colorectal cancer compared with the levels in controls or patients with diverticular disease [38]. Conversely, Kosumi et al. [24] did not find any significant association between the amount of Bifidobacteria and cancerspecific and overall mortality or any relationship with the clinical, pathological, or molecular characteristics of colorectal cancer. Despite the paucity of literature, it is likely that Bifidobacteria exert a beneficial effect during the early stages of carcinogenesis, acting as a prebiotic agent in improving epithelial defenses against infections [39]. The study by Flemer et al. [23] is the only one that focused on the analysis and comparison of tissueassociated groups of various bacteria rather than individual bacteria. In their previous work [40], the authors defined 6 mucosa-associated bacterial co-abundance groups (CAGs) and showed an increased abundance of the Firmicutes CAG 2, the Prevotella CAG, the pathogen CAG, and the Bacteroidetes CAG 2 in tissues of colorectal cancer compared with their levels in tissues of control subjects. Moreover, they showed that the pathogen CAG and the Prevotella CAG were correlated and that their gene expression levels were previously associated with decreased survival in patients with colorectal cancer. In the most recent study, the results support the idea that the two latter CAGs are in fact associated with longer survival [23]. The authors stressed the importance of further studies to explain this outcome.

The present systematic review is based on 8 original studies with variable quality and risk of bias characterized by a high degree of heterogeneity in terms of study design, sample size, patient population, clinical characteristics, bacterial sampling and detection methods, target microbiome, and target outcome. Although all studies that focused on oncological outcomes detected MAM from tumor samples and in 5 of these studies [22, 25-28], they analyzed a DNA load of $F$. nucleatum, it must be stressed that each study used different types of samples. Only Flanagan et al. and Wei et al. used fresh frozen tissue samples as opposed to formalin-fixed paraffin-embedded (FFPE) samples used in the rest of the studies. It has been shown previously that FFPE specimens have lower expression of the analyzed targets than fresh frozen samples, which is of great importance in the quantitative analysis of bacteria [41]. Three studies [22, 23, 27] analyzed the microbiome in healthy tissues from the same patient as a reference. Although this approach is a common practice in studies focusing on microbiome detection in colorectal cancer and is used to exclude interindividual microbiome differences, there is contradictory evidence whether the healthy and cancerous tissues from the same subject are representative of healthy and cancer-related microbiome composition. Finally, it must be highlighted that the included studies were carried out in different geographical areas (e.g., Europe, Asia, the USA), a feature that may influence the diversity of the intestinal microbiome [42]. The mode of subsistence and diet seem to be the most important natural factors impacting the intestinal microbiome, and diet varies between ethnic groups, nationalities, and people who live in rural or urban areas, with the latter being especially enriched in Bacteroides, Bifidobacterium, and Firmicutes [42].

The limited number of studies and the methodological heterogeneity hampered any meta-analytic approach of the present data and it should be carefully considered when interpreting the available body of evidence.

\section{Clinical impact and future perspectives}

Although the evidence remains limited, the potential relationship between intestinal microbiome composition and outcomes of colorectal cancer surgery is a promising field of research that may have compelling clinical relevance. Indeed, despite the significant advances in surgical techniques and devices, colorectal cancer surgery is still associated with a non-negligible morbidity and mortality risk. Concerning AL in particular, the role of microbiome composition may represent one missing piece to explain the susceptibility of certain patients. Indeed, detecting specific bacteria with a negative impact on anastomotic healing could help the surgeon adapting the surgical strategy (e.g., stoma vs. primary anastomosis) to the individual patient's risk level, also taking into account the presence of an "unfavorable" 
microbiome. An experimental study of animal models has already shown successful attempts to prevent AL by introducing oral phosphate and phosphate carrier compounds after low colorectal anastomosis in the presence of pathogens expressing collagenase (Pseudomonas aeruginosa, Serratia marcescens, and Enterococcus faecalis) [43].

Another appealing concept regarding the intestinal microbiome is its possible use as a biomarker for the diagnosis of colorectal cancer, as well as its predictor of cancer aggressiveness, treatment outcomes, and even response to therapy. All included studies focusing on oncological outcomes suggested that specific bacteria such as F. nucleatum or CAGs could be used as independent predictors of survival, recurrence, and mortality in colorectal cancer patients. As a high abundance of $F$. nucleatum is associated with worse oncological outcomes of surgery, its detection in tumoral tissues before surgery could help to predict a more aggressive course of the disease, therefore leading to possible strategic changes in cancer treatment, such as more radical surgery with lymph node debulking, closer surveillance intervals for early recurrence detection, and even adjusted chemotherapy regimens.

In light of these clinical perspectives, we performed a quick search on ClinicalTrial.gov to identify pertinent ongoing clinical trials. We can report of two studies assessing the relationship between microbiome and postoperative complications (NCT04005118) or anastomotic leakage (NCT03496441) in patients undergoing colorectal surgery. Both studies are observation cohort studies; the first study is ongoing whereas the second one appears to have completed the recruitment phase. Their results will substantially contribute to elucidate the characteristics of the intestinal microbiome in patients developing or not postoperative complication after colorectal surgery and will support further clinical and animal research in the field. Indeed, it remains unclear whether microbiome composition is a cause or the result of clinical outcomes in colorectal cancer patients and its characterization is so complex and influenced by so many factors that will definitely require multiple investigations [44-46].

Moreover, researchers should continue to study the impact of preoperative ATB and MBP son intestinal microbiome and subsequently on the short- and longterm postoperative outcomes. Current evidence is still inconclusive about the efficacy of prophylactic techniques or preparations to avoid complications such as AL [5]. Thus, there is an urgent need for research studies to analyze the microbiome composition in deep, to elucidate the effects (potentially beneficial or harmful) of different microbes on the processes of wound healing and development of early postoperative complications [5, 47]. Finally, research may advance looking for treatments that may influence microbiome composition to favor symbiotic and beneficial microbes that can contribute to improve colorectal surgery outcomes.

\section{Conclusions}

The present systematic review demonstrates that the current literature about the role of intestinal microbiome on colorectal cancer surgery outcomes is limited. However, there is consistency in the available data supporting a plausible linked between the intestinal microbiome composition and the occurrence of postoperative complications in colorectal cancer surgery patients. Further investigations are awaited to assess this association and elucidate whether intestinal microbiome characterization could be used as a prognostic marker in colorectal cancer patients.

\section{Supplementary information}

Supplementary information accompanies this paper at https://doi.org/10. 1186/s12957-019-1754-X.

Additional file 1: Table S1. Excluded articles and reasons for exclusion after full-text evaluation. Table S2. Risk of bias evaluation for cohort and case-control studies based on the Newcastle-Ottawa Scale. Maximum score for each item: Selection - 4, Comparability - 2, Outcome/Exposure -3 stars

\section{Acknowledgements}

The authors would like to thank the entire team of the EA 7375-EC2M3 Laboratory for their constant help and support.

\section{PRISMA 2009 checklist statement}

The authors have read the PRISMA 2009 Checklist, and the manuscript was prepared and revised according to the PRISMA 2009 Checklist.

\section{Authors' contributions}

LL and ER have equally contributed to the manuscript to concept the study design, literature search, data analysis, data interpretation, and article drafting. MCC and FG contributed to data interpretation and manuscript critical revisions. FB, IS, and NdA contributed to concept the study design, data analysis, data interpretation, and manuscript critical revision. All authors read and approved the final version of the manuscript.

\section{Funding}

No funding.

Availability of data and materials

All data and materials are available within the manuscript.

Ethics approval and consent to participate

Not applicable

Consent for publication

Not applicable

\section{Competing interests}

Pr Iradj Sobhani declares financial support from the following pharmaceutical labs to international congress assistance: Biocodex, Pfizer, Novartis, IPSEN. The other authors declare that they have no competing interests.

\section{Author details}

'Department of Digestive and Hepatobiliary Surgery, Henri Mondor University Hospital, Avenue du Maréchal de Lattre de Tassigny, 94010 Créteil, France. ${ }^{2}$ EA 7375-EC2M3, Université Paris Est - UPEC, 51, Avenue du Maréchal de Lattre de Tassigny, 94010 Créteil, France. ${ }^{3}$ Department of Odontology, Rothschild University Hospital, 5 Rue Santerre, 75012 Paris, and 
University Paris Diderot, 75006 Paris, France. ${ }^{4}$ Gastroenterology and Endoscopy Unit, University Hospital of Parma, University of Parma, Via Gramsci 14, 43126 Parma, Italy. ${ }^{5}$ Department of Hepato-Pancreato-Biliary and Liver Transplant Surgery, Queen Elizabeth University Hospitals Birmingham NHS Foundation Trust, Birmingham, UK. ${ }^{6}$ Department of Gastroenterology, Henri Mondor University Hospital, Avenue du Maréchal de Lattre de Tassigny, 94010 Créteil, France.

\section{Received: 10 August 2019 Accepted: 21 November 2019 Published online: 02 December 2019}

\section{References}

1. Jalanka-Tuovinen J, Salonen A, Nikkila J, Immonen O, Kekkonen R, Lahti L, et al. Intestinal microbiota in healthy adults: temporal analysis reveals individual and common core and relation to intestinal symptoms. PLoS One. 2011;6(7):e23035.

2. Morowitz MJ, Babrowski T, Carlisle EM, Olivas A, Romanowski KS, Seal JB, et al. The human microbiome and surgical disease. Ann Surg. 2011;253(6): 1094-101.

3. Lin C, Cai X, Zhang J, Wang W, Sheng Q, Hua H, et al. Role of gut microbiota in the development and treatment of colorectal cancer. Digestion. 2019;100(1):72-8.

4. Ralls MW, Miyasaka E, Teitelbaum DH. Intestinal microbial diversity and perioperative complications. JPEN J Parenter Enteral Nutr. 2014;38(3):392-9.

5. Bachmann R, Leonard D, Delzenne N, Kartheuser A, Cani PD. Novel insight into the role of microbiota in colorectal surgery. Gut. 2017:66(4):738-49.

6. Arvans DL, Vavricka SR, Ren H, Musch MW, Kang L, Rocha FG, et al. Luminal bacterial flora determines physiological expression of intestinal epithelial cytoprotective heat shock proteins 25 and 72. Am J Physiol Gastrointest Liver Physiol. 2005;288(4):G696-704.

7. Alverdy JC. Ionic modulation of bacterial virulence and its role in surgical infection. Surg Infect. 2018;19(8):769-73.

8. Souza DG, Vieira AT, Soares AC, Pinho V, Nicoli JR, Vieira LQ, et al. The essential role of the intestinal microbiota in facilitating acute inflammatory responses. J Immunol (Baltimore, Md: 1950). 2004;173(6):4137-4146.

9. Stavrou G, Kotzampassi K. Gut microbiome, surgical complications and probiotics. Ann Gastroenterol. 2017:30(1):45-53.

10. Gaines S, Shao C, Hyman N, Alverdy JC. Gut microbiome influences on anastomotic leak and recurrence rates following colorectal cancer surgery. Br J Surg. 2018;105(2):e131-e41.

11. Mokhles S, Macbeth F, Farewell V, Fiorentino F, Williams NR, Younes RN, et al. Meta-analysis of colorectal cancer follow-up after potentially curative resection. Br J Surg. 2016;103(10):1259-68.

12. Yun JA, Huh JW, Kim HC, Park YA, Cho YB, Yun SH, et al. Local recurrence after curative resection for rectal carcinoma: the role of surgical resection. Medicine. 2016;95(27):e3942.

13. Aoyama T, Oba K, Honda M, Sadahiro S, Hamada C, Mayanagi S, et al. Impact of postoperative complications on the colorectal cancer survival and recurrence: analyses of pooled individual patients' data from three large phase III randomized trials. Cancer medicine. 2017:6(7):1573-80.

14. Tevis SE, Kohlnhofer BM, Stringfield S, Foley EF, Harms BA, Heise CP, et al. Postoperative complications in patients with rectal cancer are associated with delays in chemotherapy that lead to worse disease-free and overall survival. Dis Colon Rectum. 2013;56(12):1339-48.

15. Higgins JPTTJ, Chandler J, Cumpston M, Li T, Page MJ, Welch VA, editors. Cochrane handbook for systematic reviews of interventions. 2nd edition. Chichester (UK): John Wiley \& Sons; 2019.

16. Weiser MR. AJCC 8th edition: colorectal cancer. Ann Surg Oncol. 2018;25(6): 1454-5.

17. Ringel Y, Maharshak N, Ringel-Kulka T, Wolber EA, Sartor RB, Carroll IM. High throughput sequencing reveals distinct microbial populations within the mucosal and luminal niches in healthy individuals. Gut Microbes. 2015;6(3): 173-81.

18. Rahbari NN, Weitz J, Hohenberger W, Heald RJ, Moran B, Ulrich A, et al. Definition and grading of anastomotic leakage following anterior resection of the rectum: a proposal by the International Study Group of Rectal Cancer. Surgery. 2010;147(3):339-51

19. organisation Wh. Global guidlines for the prevention of surgical site infection World health organisation; 2016. 184 p.

20. Wolthuis AM, Bislenghi G, Fieuws $S$, de Buck van Overstraeten A Boeckxstaens G, D'Hoore A. Incidence of prolonged postoperative ileus after colorectal surgery: a systematic review and meta-analysis. Colorectal disease : the official journal of the Association of Coloproctology of Great Britain and Ireland. 2016;18(1):01-9.

21. Stang A. Critical evaluation of the Newcastle-Ottawa scale for the assessment of the quality of nonrandomized studies in meta-analyses. Eur J Epidemiol. 2010;25(9):603-5.

22. Flanagan $L$, Schmid J, Ebert M, Soucek P, Kunicka T, Liska V, et al. Fusobacterium nucleatum associates with stages of colorectal neoplasia development, colorectal cancer and disease outcome. European journal of clinical microbiology \& infectious diseases : official publication of the European Society of Clinical Microbiology. 2014;33(8):1381-90.

23. Flemer B, Herlihy M, O'Riordain M, Shanahan F, O'Toole PW. Tumourassociated and non-tumour-associated microbiota: Addendum. Gut Microbes. 2018;9(4):369-73

24. Kosumi K, Hamada T, Koh H, Borowsky J, Bullman S, Twombly TS, et al. The amount of Bifidobacterium genus in colorectal carcinoma tissue in relation to tumor characteristics and clinical outcome. Am J Pathol. 2018:188(12): 2839-52.

25. Mima K, Nishihara R, Oian ZR, Cao Y, Sukawa Y, Nowak JA, et al. Fusobacterium nucleatum in colorectal carcinoma tissue and patient prognosis. Gut. 2016;65(12):1973-80.

26. Wei Z, Cao S, Liu S, Yao Z, Sun T, Li Y, et al. Could gut microbiota serve as prognostic biomarker associated with colorectal cancer patients' survival? A pilot study on relevant mechanism. Oncotarget. 2016;7(29):46158-72.

27. Yan X, Liu L, Li H, Qin H, Sun Z. Clinical significance of Fusobacterium nucleatum, epithelial-mesenchymal transition, and cancer stem cell markers in stage III/IV colorectal cancer patients. OncoTargets and therapy. 2017;10: 5031-46.

28. Yu T, Guo F, Yu Y, Sun T, Ma D, Han J, et al. Fusobacterium nucleatum promotes chemoresistance to colorectal cancer by modulating autophagy. Cell. 2017;170(3):548-63.e16.

29. van Praagh JB, de Goffau MC, Bakker IS, van Goor H, Harmsen HJM, Olinga $P$, et al. Mucus microbiome of anastomotic tissue during surgery has predictive value for colorectal anastomotic leakage. Ann Surg. 2019;269(5): 911-6.

30. van Praagh JB, de Goffau MC, Bakker IS, Harmsen HJ, Olinga P, Havenga K Intestinal microbiota and anastomotic leakage of stapled colorectal anastomoses: a pilot study. Surg Endosc. 2016:30(6):2259-65.

31. Riviere A, Selak M, Lantin D, Leroy F, De Vuyst L. Bifidobacteria and butyrateproducing colon bacteria: importance and strategies for their stimulation in the human gut. Front Microbiol. 2016;7:979

32. Kostic AD, Chun E, Robertson L, Glickman JN, Gallini CA, Michaud M, et al. Fusobacterium nucleatum potentiates intestinal tumorigenesis and modulates the tumor-immune microenvironment. Cell Host Microbe. 2013; 14(2):207-15.

33. Shang FM, Liu HL. Fusobacterium nucleatum and colorectal cancer: a review. World journal of gastrointestinal oncology. 2018;10(3):71-81.

34. Li YY, Ge QX, Cao J, Zhou YJ, Du YL, Shen B, et al. Association of Fusobacterium nucleatum infection with colorectal cancer in Chinese patients. World J Gastroenterol. 2016;22(11):3227-33.

35. Purcell RV, Pearson J, Aitchison A, Dixon L, Frizelle FA, Keenan Jl. Colonization with enterotoxigenic Bacteroides fragilis is associated with early-stage colorectal neoplasia. PLoS One. 2017:12(2):e0171602.

36. Viljoen KS, Dakshinamurthy A, Goldberg P, Blackburn JM. Quantitative profiling of colorectal cancer-associated bacteria reveals associations between fusobacterium spp., enterotoxigenic Bacteroides fragilis (ETBF) and clinicopathological features of colorectal cancer. PLoS One. 2015;10(3): e0119462.

37. Tojo R, Suarez A, Clemente MG, de los Reyes-Gavilan CG, Margolles A, Gueimonde $\mathrm{M}$, et al. Intestinal microbiota in health and disease: role of bifidobacteria in gut homeostasis. World J Gastroenterol. 2014;20(41):15163-76.

38. Borges-Canha M, Portela-Cidade JP, Dinis-Ribeiro M, Leite-Moreira AF, Pimentel-Nunes P. Role of colonic microbiota in colorectal carcinogenesis: a systematic review. Revista espanola de enfermedades digestivas : organo oficial de la Sociedad Espanola de Patologia Digestiva. 2015;107(11):659-71.

39. Fukuda S, Toh H, Hase K, Oshima K, Nakanishi Y, Yoshimura K, et al. Bifidobacteria can protect from enteropathogenic infection through production of acetate. Nature. 2011:469(7331):543-7.

40. Flemer B, Lynch DB, Brown JM, Jeffery IB, Ryan FJ, Claesson MJ, et al. Tumour-associated and non-tumour-associated microbiota in colorectal cancer. Gut. 2017;66(4):633-43. 
41. Luder Ripoli F, Mohr A, Conradine Hammer S, Willenbrock S, HewickerTrautwein M, Hennecke $\mathrm{S}$, et al. A comparison of fresh frozen vs. formalinfixed, paraffin-embedded specimens of canine mammary tumors via branched-DNA assay. Int J Mol Sci. 2016;17:5.

42. Gupta VK, Paul S, Dutta C. Geography, ethnicity or subsistence-specific variations in human microbiome composition and diversity. Front Microbiol. 2017;8:1162.

43. Wiegerinck M, Hyoju SK, Mao J, Zaborin A, Adriaansens C, Salzman E, et al. Novel de novo synthesized phosphate carrier compound ABA-PEG20k-Pi20 suppresses collagenase production in Enterococcus faecalis and prevents colonic anastomotic leak in an experimental model. Br J Surg. 2018;105(10): 1368-76.

44. Wirbel J, Pyl PT, Kartal E, Zych K, Kashani A, Milanese A, et al. Meta-analysis of fecal metagenomes reveals global microbial signatures that are specific for colorectal cancer. Nat Med. 2019;25(4):679-89.

45. Thomas AM, Manghi P, Asnicar F, Pasolli E, Armanini F, Zolfo M, et al. Metagenomic analysis of colorectal cancer datasets identifies cross-cohort microbial diagnostic signatures and a link with choline degradation. Nat Med. 2019;25(4):667-78.

46. Yachida S, Mizutani S, Shiroma H, Shiba S, Nakajima T, Sakamoto T, et al. Metagenomic and metabolomic analyses reveal distinct stage-specific phenotypes of the gut microbiota in colorectal cancer. Nat Med. 2019;25(6): 968-76.

47. Vo E, Massarweh NN, Chai CY, Tran Cao HS, Zamani N, Abraham S, et al. Association of the addition of oral antibiotics to mechanical bowel preparation for left colon and rectal cancer resections with reduction of surgical site infections. JAMA surgery. 2018;153(2):114-21.

\section{Publisher's Note}

Springer Nature remains neutral with regard to jurisdictional claims in published maps and institutional affiliations.

Ready to submit your research? Choose BMC and benefit from:

- fast, convenient online submission

- thorough peer review by experienced researchers in your field

- rapid publication on acceptance

- support for research data, including large and complex data types

- gold Open Access which fosters wider collaboration and increased citations

- maximum visibility for your research: over $100 \mathrm{M}$ website views per year

At $\mathrm{BMC}$, research is always in progress.

Learn more biomedcentral.com/submissions 